\title{
Cyber-relations in the Field of Home Computer Use for Leisure: Bourdieu and teenage technological experts
}

\author{
NICOLA F. JOHNSON \\ University of Wollongong, Australia
}

\begin{abstract}
This article highlights the practice of a group of New Zealand teenagers who are considered by their family and themselves to be technological experts. Drawing on Pierre Bourdieu's key concepts of habitus, field and capital, this text identifies and discusses the cyber-relations that constitute the practice in the field of home computer use for leisure. The purpose of this article is to claim that though this field is predominantly a field of leisure, these are valid sites of informal learning. As almost all of the experts in the study gained their expertise through independent means, with minimal input from their schooling, discussion focuses on what these informal trajectories to technological expertise might mean for pedagogy and formal learning within schools.
\end{abstract}

\section{Introduction}

The word cyber-relations may bring to mind connotations of netiquette, Internet public relations, Internet affairs, Internet pornography, cybersex, and online or virtual relationships. In this article, I seek to coin an accurate term that explains the social practice that constitutes the field of home computer use for leisure. Cyber-relations are relations or communications using information and communication technologies (ICTs) between the agent and others who are not seen. Such a term is needed in order to help us identify and think about how online interactions exist and are played out in the lives of young people.

The research project described in this article sought to understand what expertise might look like, and then trace how those who have it have developed it. Instead of starting with an absence of expertise, I began with the presence of expertise and used Bourdieu's key concepts to map the habitus and dispositions of teenage technological experts and explain the various forms of capital they have negotiated within this field. This article specifically focuses on how the teenage experts related to other people within the field, which I have defined as cyber-relations. These cyberrelations constitute the social practice in this field of home computer use for leisure.

The article begins with a brief description of Bourdieu's concepts of habitus, field and capital. These Bourdieuian concepts are useful to explain the social practice of these teenage technological experts as I focus on the structure of the field in terms of the relations between those involved (Grenfell, 2004), and the cultural practices associated with cyber-relations. This social practice can be identified through theorizing the habitus of those positioned in the field, the forms of capital the participants possess, and the predominant field in which they are positioned. Bourdieu's concepts were pertinent to this research, providing a useful framework to understand the practice within this field. After I introduce the methodology and the participants in the project, some implications for pedagogy and formal learning are presented from identification of the cyber-relations within this field. 


\section{Habitus, Field and Capital}

Bourdieu's formula for studying social practice was written as '[(habitus) (capital)] + field $=$ practice' (Bourdieu, 1984, p. 101). Each of these terms is now explained.

Habitus is a concept used to explain the dispositions that influence individuals to become who they are, and yet also includes the conditions of existence (Bourdieu, 1990) which are displayed every day in their relations to society in and through individual activities. For Bourdieu, habitus is fundamentally connected to the field(s) within which it is developed (Grenfell \& James, 2004). The useful image of 'fish in water' (Grenfell \& James, 1998, p. 14) describes the mutually constitutive nature of habitus and field, as the concepts are based on 'identical generating principles', with 'structural homologies between the two' (Grenfell \& James, 1998, p. 16).

Bourdieu (1992) defined a field as a 'configuration of relations between positions objectively defined, in their existence and in the determinations they impose upon the occupants, agents or institutions' (pp. 72-73). A field was Bourdieu's metaphor for representing sites of cultural practice (Webb et al, 2002). In the case of this study, the field of interest was the field of home computer use for leisure of teenage technological experts. The conventions and organization within a field determine the appropriate discourses and activities that are used. Within each field (social space), there is that which is excluded, and that which is included. These contexts (fields) shape and produce practice.

The term capital has multiple meanings within Bourdieu's framework. Bourdieu uses economic capital as the basis for writing about and developing the concepts of other forms of capital, that is, cultural, social, and symbolic. When one speaks about a field, one includes the institutions, rules, rituals, conventions, categories, and structured contexts that make up the hierarchy of accepted processes and practices, all of which is where capital is determined (Facer et al, 2003). To explain further the link between field and capital:

\footnotetext{
Bourdieu reasons that capital attracts capital, as like attracts like, and the various forms are, in many ways, inter-convertible. So, for example, high academic qualifications traditionally tend to 'buy' good jobs with good salaries. Yet, at the same time, as 'players' in the market acquire more capital, it becomes devalued. For example, there is qualification inflation, where over time a given level of certification no longer guarantees the same prestigious jobs. Capital exists in ever changing configurations in relation to the fields which generate it, and, the values of its three forms are constantly being renegotiated in implicit and explicit ways. (Grenfell \& James, 1998, p. 21)
}

In this article, I explain these elements and focus on the structure of the field in terms of the relations between those involved (Grenfell, 2004), and who those actors are, and the outworkings of embodied relationships, including cyber-relations.

\section{Method}

The qualitative study involved observations and interviews with eight teenagers aged 13-17. Five boys and three girls participated and each attended one of various secondary schools located within a provincial city in New Zealand. All of the participants claimed to be a technological expert. Each of the participants rated themselves as at least a three on a scale of 1-5, one being a 'great' expert and five being a 'good' expert. None of them chose to rank themselves as not being an expert, and, interestingly, no one rated themselves as a one (a great expert): the ratings were somewhere between a 'good expert' and 'becoming a great expert'.

Participants were recruited using snowball sampling (Patton, 2002), a strategy that relies on persons to recommend others who fit certain criteria. For this study, the criteria were that the participant had to be recommended and identify as a technological expert, be aged from 13 to 17 , and be located within the local area. As it was not an aim to make generalisable or representative claims about all teenagers, it was fitting that the study used purposeful sampling to select information-rich cases for in-depth study. When seeking out participants for the study, I interviewed teenagers who I knew personally and asked them what they thought technological experts were and if they could recommend anyone whom they considered to be a teenage technological expert. I selected the first eight participants who deemed themselves to be 
'technological experts', consented to be involved in the study, and whom I could observe and interview over a period of four months in 2005. This decision was made regardless of gender, school, and age. Because this study sought to focus on obtaining rich data, I did not try to recruit more than a small number of participants. An area for further research is to perhaps compare the practice of experts with 'non-experts'.

The research project used a qualitative inquiry approach utilizing interviews and observations. Often aligned with case-study techniques, the qualitative inquiry approach was used to explore the habitus and capital surrounding the acquisition of computer expertise in the field of home computer use for leisure. In this study, the use of interviews and observations was not only part of qualitative research methodology, but also part of Bourdieu's anthropological roots. I focused on examining particular phenomena, understanding the phenomena in depth, and from that analysing the data using Bourdieu's theories combined with a feminist lens.

According to Merriam (1998), humans are the best instruments for examining human data, especially phenomena in sociocultural contexts (Schwandt, 1990). The qualitative data collection methods employed the researcher as the data collection instrument, and involved observations and interviews.

\section{Observations}

The data gathered for the qualitative study were collected through employing observations and interviews. Initially, I conducted an observation with each participant. The observations were approximately an hour long each, and consisted of me observing the teenagers using a computer in a manner that they described as typical of their use on any given day. During the observation, I recorded what they did, and how they did it, and recorded most of what was said to me. Sometimes I asked questions to clarify what it was they were doing and why.

It should be noted that I was not a participant observer; I was in a fact a detached observer (Olson, n.d.). All observations were completed beside their computer, while they were using it. One observation of Jake was completed as he prepared and conducted a sound and lighting gig.

\section{Interviews}

Interviewing offers researchers access to people's ideas, thoughts, and memories in their own words rather than in the words of the researcher (Bourdieu, 1999; Patton, 2002). This enables the interview to be of benefit to the interviewee, and lessens the influence of the interviewer on the thoughts and words of the interviewee. The first objective in using an interview is to allow respondents to tell their own story in their own terms (Bourdieu, 1999). The interview 'aims at a true conversion of the way we look at other people in the ordinary circumstances of life' (Bourdieu, 1999, p. 614). During the interview, one needs to 'perceive and monitor on the spot, as the interview is actually taking place, the effects of the social structure within which it is occurring' (Bourdieu, 1999, p. 608, emphasis in original). Furthermore, the interview encourages the social processes of talking and listening to achieve the goal of understanding.

Structured interviews are those which are conducted with a list of predetermined questions (Merriam, 1998). Though the interviews I conducted were of the formal nature of structured interviews, they were somewhat informal as I did not ask only the questions on my list; sometimes I did not ask all of the listed questions, nor did I ask them in the same order. I employed the use of open-ended questions so that in the answers the interviewee could answer how s/he wished. Before and during each interview, I stressed to the participants that they did not have to answer any question they did not wish to, and that included questions that I asked on the spot. I did, however, have a list of questions that I wished to ask participants and gave them the list of the questions before the interview, so that (a) they had a chance to think about the questions, and (b) they could make a choice about what questions to answer and not answer.

The second session was an interview. The third session usually combined an observation and an interview. As the observations were conducted prior to the first interview, the interview questions were informed by the previously occurring observations. The third interview/observation drew on both the previous observation and previous interview in order to 
delve deeper into understanding their social practice. Interviews were conducted at their home, sometimes beside their computer, but usually in a place of personal comfort for the participants, like the dining table, family room, bedroom, or lounge. Each session was approximately one hour in length, and some sessions were longer owing to an extended observation period (1.5 hours, for example). Table I summarizes some of the demographics of the eight participants in the study.

\begin{tabular}{|c|c|c|c|c|c|c|c|c|}
\hline Name & Anne & Charli & Chris & Jake & Joe & Lisa & Tom & Tim \\
\hline Sex & F & F & M & M & M & F & M & M \\
\hline Age & $14-15$ & $13-14$ & 13 & $16-17$ & 14 & $15-16$ & $16-17$ & 16 \\
\hline $\begin{array}{l}\text { Location of } \\
\text { computer }\end{array}$ & Kids' wing & Hall & $\begin{array}{l}\text { Dining } \\
\text { room }\end{array}$ & Kids' wing & $\begin{array}{l}\text { Dining } \\
\text { room }\end{array}$ & Lounge & Bedroom & Bedroom \\
\hline $\begin{array}{l}\text { Type of } \\
\text { Internet access }\end{array}$ & $\begin{array}{l}\text { Broadband } \\
\text { wireless }\end{array}$ & Dial-up & Dial-up & Broadband & Dial-up & Dial-up & Broadband & Broadband \\
\hline Year & 10 & 10 & 9 & 12 & 10 & 11 & 12 & 12 \\
\hline Marks/ grades & $\begin{array}{l}\text { Average to } \\
\text { above }\end{array}$ & $\begin{array}{l}\text { Above } \\
\text { average }\end{array}$ & $\begin{array}{l}\text { Above } \\
\text { average }\end{array}$ & Average & $\begin{array}{l}\text { Above } \\
\text { average }\end{array}$ & Average & $\begin{array}{l}\text { Above } \\
\text { average }\end{array}$ & Average \\
\hline $\begin{array}{l}\text { Type of school } \\
\text { (public }= \\
\text { government or }\end{array}$ & $\begin{array}{l}\text { Public girls } \\
\text { years 9-13 }\end{array}$ & $\begin{array}{l}\text { Public } \\
\text { co-ed } \\
\text { years }\end{array}$ & $\begin{array}{l}\text { Public } \\
\text { co-ed } \\
\text { years }\end{array}$ & $\begin{array}{l}\text { Public co-ed } \\
\text { years } 9-13\end{array}$ & $\begin{array}{l}\text { Public } \\
\text { co-ed } \\
\text { years }\end{array}$ & $\begin{array}{l}\text { Public } \\
\text { co-ed } \\
\text { years }\end{array}$ & $\begin{array}{l}\text { Public co-ed } \\
\text { years 9-13 }\end{array}$ & $\begin{array}{l}\text { Public co-ed } \\
\text { years 9-13 }\end{array}$ \\
\hline state school) & & $7-13$ & $9-13$ & & $9-13$ & $7-13$ & & \\
\hline
\end{tabular}

Table I. Summary of participants.

Informed consent was obtained from both the participants and their parents, and pseudonyms have been used to prevent identification. The qualitative data collected was analysed drawing on the key themes from Bourdieu's theory of practice, including (but not only) habitus, field, and capital. To introduce the participants, I now present a brief description of each participant, focusing on their specific cyber-relations.

\section{Anne}

For Years 7 and 8 (in a New Zealand Intermediate school, approximate age of 11-13), Anne was in a classroom where each child had her or his own laptop, i.e. a specifically named 'laptop classroom'. Anne did not use the computers at her current secondary school (Years 9-13) very often and did not attend any computing classes. She was adamant that the computer classes for years 9 and 10 at her school were very easy, and were far too simple for her level of expertise. She was considering a career in computers but was not sure as she expected to find computer programming boring. Anne often used the Internet and instant chat (MSN) while watching television. She believed she had expertise in certain programs, and thought expertise was program-specific. She said she was not an expert of 'the whole computer'.

\section{Charli}

Charli was a member of an online community, where members write poetry and prose to share with one another. People were able to view different genres of poems in this community and write comments on others' poems. Charli first posted an original poem two or three years ago and was 'quite proud that I'd done something myself and I knew everything about how to do it'. Charli met many people through that site and from there was recommended another website that allowed people to create their own websites, from which she created her own. Many of her associated friends from the poetry site also had their own website with this other community. Charli spent a lot of time creating her own website. Charli had friends whom she had met online whom she calls her 'friends overseas': 'Yeah, I love my friends overseas. I love them. Sometimes like I think I'm closer to them than I am like with people here, just because they're that, like I just have that much more space, cause I love, I need my personal space’. 
Lisa

Lisa had had a computer for about three years (since Year 8). Lisa said she was usually on the computer from 4 to 6 p.m., then her brother had a turn, then her mum, and then 'some time later' she would get back on. Lisa taught friends and family how to use the Internet, use sites, make sites, download music, and make (burn) CDs. She played an important role in others' lives through recommending sites and showing people how to use the computer for different purposes. Lisa did not seem to have a role model or someone who had shown or taught her how to use the computer or Internet. She had her own way of learning new things on the computer: 'Um, probably like, go round the very edges of it first and then just see what happens and then just keep moving in further, to what's like in the centre, or something. Yeah [laughs]. Like working round the idea of something'. Lisa believed she learned from herself when she was on the computer.

Charli and Lisa created their own personal websites using 'Piczo' [1], which allows users to create comprehensive personal websites that do not require html code. Arguably, it is more difficult to use than default 'MySpace' or 'Blogger' pages, and has bigger scope in variety in designing multiple web pages on a website. Lisa and Charli were close friends and Lisa first introduced Charli to Piczo and to the poetry community.

The five boys all attended the same secondary school, though apart from Tom and Tim (who were good friends), they were unknown to one another.

\section{Chris}

Chris had been using a computer since he was two years old. He spent a lot of time playing video/computer games, but this was usually on his PlayStation 2 machine. He viewed his computer learning and use as fun. Chris believed he was a computer expert, but that this had been ignored and somewhat discouraged at his current school. He listed many software programs that he believed he was skilled at using. The primary school he formerly attended played a significant role in the development and encouragement of his expertise. Chris mentioned that his friends found his computer skills useful. It was important to Chris to be able to help others through using his computer expertise.

\section{Jake}

Jake was the network administrator for his secondary school and was responsible for 140 networked computers. Sometimes he got paid for the out-of-school work he did for his school through managing their hall/auditorium. Jake did sound and lighting at a church with a modern sound and lighting system, and for his secondary school, which was also known as a mini-concert venue in the local area. He also worked for a large, local concert venue once or twice a month and had learnt a lot from the employees of that venue. He did video work, including the 'editing and running' of videos. He was also the official sound and lighting person for his church's youth band. Jake was the manager for the local branch of a lighting company that was based in a bigger city in New Zealand, and provided a service to non-profit organizations by charging them only small amounts to do shows and events. He was extremely busy, saying 'yes' to all requests for his expertise. His technical knowledge gave him a sense of value. Jake claimed he spent about six hours a day in front of a computer, two hours a day behind a lighting desk, and about nine hours a week behind a sound desk.

$$
\text { Joe }
$$

Joe saw computer expertise as invaluable and inseparable from his potential career interests. He wanted to be an astronomer. Joe had many interests and he researched them on the Internet. They included space and flight, scientific learning sites, cricket, soccer, music, current events, and the latest games. He also visited sites about The Da Vinci Code (authored by Dan Brown), and had an interest in art and art history, weather, climate change, and astronomy (planetarium websites and 
CyberSky). He also checked on details for the latest mobile phone ring tones, and information on his favourite music bands. He read widely, especially science fiction, as he believed sci-fi 'extends your imagination'.

\section{Tom}

Tom spent most of his time online playing the game, World of Warcraft (WOW). Tom evaluated his time as $70 \%$ games, $10 \%$ homework and $20 \%$ web design ('maybe, yeah'). If Tom was at home, he was usually on his computer. Tom had 45 websites (on his record) that he had designed since the age of 10 or 11 . He used Macromedia Dreamweaver to design the pages, though he knew HTML (a computer programming language). He mainly designed websites to promote Counterstrike gamers (another online game) but had also designed them to develop his portfolio and gain experience.

\section{Tim}

Tim spent two to three hours per weekday on the computer, and approximately seven hours per weekend day and seven hours per day in the school holidays. Tim had a paper run from which he earned money to pay for things such as his WOW subscription. Tim had no idea of what he wanted to do when he left school and did not seem to be involved in many things other than computers. He had not looked at what he could do to make the most of any opportunities that came his way, even with regard to computers: 'I don't really take, like use the skills that I've got on the computer anywhere else'.

Tim and Tom had been good friends since they first went to school together. Tom recommended Tim to me as someone who was happy to be involved in the research, and someone whom Tom considered to be an expert.

Jake, Tom, Tim and Charli had almost exclusive use of a home computer. Jake, Tom and Tim had bought or been given their computer for their exclusive use. Anne's computer was shared with her younger sister, though her sister had her own additional iBook for her school and personal use. Chris had his own laptop at his father's house for his exclusive use (along with broadband Internet), but had to share one desktop computer with his mother and sister at his mother's house (which had dial-up Internet). Joe shared the home computer with his sister, but was the main user. Lisa shared the home computer with her brother and mother, but also was the main user.

\section{Observations of Cyber-relations in the Field of Home Computer Use for Leisure}

The cyber-relations I observed have shaped how the young people in this study developed technological expertise at home, mainly through using computers for leisure. For seven of the eight participants, their home computer use was their predominant and preferred form of leisure. However, this site of leisure within an informal setting provided them with the means of being able to develop computing knowledge and skill to learn from and teach others about their areas of interest.

The variety of people they interacted with was notable. These online persons had expertise in various areas and were of various ages, positioned in various locations. Some of those whom the participants interacted with also existed in face-to-face friendships, but many other interactions did not take place in person, nor were they personified. The cyber-relations that made up this field of home computer use for leisure consisted of some or all of the following relations:

- with other technological experts;

- with others online;

- with their own computer, as a personal extension (Cuthell, 2002) of themselves (an argument of medium theory); and

- with others who were economically privileged (Johnson, 2009). 
There were multiple types of activities that comprised this social practice. The participants I observed, both male and female, engaged in the following social practice that constituted the cyberrelations:

- MSN and other forms of instant chat/messaging (e.g., iChat);

- surfing (browsing) the Web;

- checking and sending email;

- researching information for homework tasks;

- designing websites

- researching popular culture (e.g. television shows, celebrities, products)*;

- playing games - online and offline;

- configuring their own preferences for the computer;

- downloading music for their MP3 players ${ }^{\star}$; and

- writing compact discs of music downloaded from the Internet ${ }^{\star}$.

Not all the participants engaged in the activities marked with an asterisk, in that I did not observe these activities with every participant. In the interviews, the participants mentioned and described activities that I did not observe, and those activities included spending time on the computer with their friends and family, sharing a task or project, playing a game, or exploring a topic together. While the first four activities were sometimes completed also at school, or at other computers at various locations, all of the activities were conducted at home on the computer that they mainly used. The participants' online interactions existed when using their computer in this field of home computer use for leisure.

\section{The Performance of Expertise in this Field of Home Computer Use for Leisure}

Within this field of home computer use for leisure by teenage technological experts, the practice involved schoolwork and leisure, including personal development and personal expression. There were cyber-relations involved in the participants' use of computers at the Internet for research, whether teacher-directed, self-directed or interest-related. These types of overt practices were evident in the participants' use of computers as detailed above. Many of the participants contacted fellow students through instant chat forums to find out about homework requirements and assignment expectations. The last three areas of leisure, personal development and personal expression inherently involved the participants' alignment with consumer media culture (Kenway \& Bullen, 2001), and technological activities associated with being positioned in a digital world. I now explain these three areas of practice.

Regarding the practice of leisure, it seemed that the boys were more involved in this field of home computer use for leisure with various enterprises and foci within the field, whereas the girls had other, additional fields that they were involved in and focused on. Anne and Lisa appeared to have developed and/or accumulated their capital in various fields over and above the main field I am discussing, whereas the boys had their capital focused on the field of home computer use by teenage experts and the fields within that field. To explain further, Anne was involved extensively in her chosen sports of netball and rowing. Lisa played in two soccer teams and had interests and involvement in her Maori culture. Lisa separated her schooling from her leisure activities on the computer, but had other interests and hardly used the computer on the weekends because she was too 'busy'. Charli and Chris both had drama lessons. Joe was involved in seasonal sports (cricket and soccer), but not extensively. Tim delivered newspapers on his bike, which took him half an hour to do each day after school (he and Jake were the only ones who had part-time employment). Tom played soccer once a week. Charli, Tim, Tom and Jake were almost always on their computer. Jake was hardly ever at home because he was involved in his technological activities, and claimed that he probably spent at least six hours a day behind a computer.

In the field of home computer use for leisure, game playing could be considered another field. Tim and Tom were the most avid game players in that my observation time with them almost always included watching them play online games (WOW). For the three girls, game playing took up only a small percentage of their time. Tim, Tom and Jake all mentioned that they had used discussion boards. Tim and Tom used discussion boards for consultation regarding games and the 
like, and Jake for help with running the Macintosh network for his school. Joe belonged to a number of email subscription lists that sent him emails about topics and brands he was interested in knowing about. The girls did not mention any of these aspects.

Personal development and personal expression also comprised this field of leisure. With regard to personal development, I believe that the participants' interest in various topics ties in with this field. Lisa's main preoccupation in this area was finding and downloading music. Joe's research into scientific topics (especially astronomy), Jake's vocations with sound, lighting, and the school network, and Tom's website design may lead to possible professional vocations.

Personal expression was important for both Lisa and Charli in the construction of their websites, but more so for Charli, who also used poetry for personal expression, and could be described as having a troubled disposition; therefore the need for personal expression could be argued as being important to her. All of the participants used online forums to explore and express their personality.

Tom seemed to believe that he was 'just normal' and that his expertise simply comprised the necessary skills for the field/career he was interested in. The status of expertise with other participants was not as valued as with Tom. Perhaps Tom believed his skill was routine - run of the mill - whereas a generation older than him believes that he and all others of that age are technological experts. This is similar to the belief that it once was routine for all older women to be able to sew and mend clothes - an embodied form of social capital that was arguably valued and somewhat necessary up until the 1980s, from when it became cheaper to purchase clothes already made, and buy new clothes instead of repairing old ones.

\section{Discursive Interactions within Cyber-relations}

My analysis of the cyber-relations in this field of home computer use for leisure included focusing on the way that these particular social agents acted and interacted with one another and learned from one another. These interactions are reflective of the way some teenagers go about finding out about the latest fashion, fad, or trend, and how this is shared discursively with their friends online and face to face. Let me give three specific examples.

First, a discourse or social practice that was perpetuated in this field is one of 'What is the latest?' This focus dictates that agents need to be interested to keep up with the play, continue their friendships, know about the latest gadgets, add to their wish list, and develop their networks. This is expressed by questions such as, 'What kind of mobile phone do you have?' or 'How long have you had your iPod?' or 'Are you on MSN?' and 'Have you seen this website? It's so cool'. The time involved to be able to ask and answer all these things dictates that these teenagers are reliant on technology more than ever before. Keeping up with the 'latest' requires economic capital to purchase commodities and update software preferences. Those who are without will always struggle to exist and compete with these agents who 'have' (Johnson, 2004). So, having a computer and MSN and access to the Internet requires economic capital, and being able to negotiate these interfaces is a form of cultural capital in this field. The attainment of expertise in this field leads to the attainment of social capital in this field (Johnson, 2009). This can be argued to be part of the habitus of some teenage technological experts.

Secondly, experience was gained in this field through continuing interaction in order to learn the 'stakes of the game' (Bourdieu, 2000, p. 151). For example, phrases such as 'What are you doing?', 'How do you do that?' and 'What's that for?' are common expressions that encourage learning, in order to be seen as up with the play, and in some ways in order to be included as part of the group. This can be referred to as 'doxic' practice. Doxa and doxic refer to what is the accepted way of thinking and acting in a field (Lovell, 2000; Grenfell, 2004). By accepting the doxic practice of finding out what others are doing, and incorporating that practice into their own practice, they become agents within this field and within others, which further perpetuates the acceptable and similar practices of others. As Moi (1991) claimed, 'all agents in the field to some extent share the same habitus' (p. 1022). The boundaries of this field are becoming stronger in their construction.

Thirdly, expertise was performed in the field as an individual, and it was normally a private practice, though sometimes it was shared with friends who would sit beside them while they 
'played' on the computer together. Arguably, their performance of expertise was more often shared with others, that is, peers, who were online, and most of that practice was synchronous. The only instance of asynchronous interaction happened when they sent electronic mail.

These previous sections have identified and outlined the feel of the game (describing the field and associated activities) within the field of home computer use for leisure by teenage technological experts. As Bourdieu stated, 'the game presents itself to someone caught up in it, absorbed in it, as a transcendent universe, imposing its own ends and norms unconditionally' (Bourdieu, 2000, p. 151).

\section{Implications for Formal Learning}

The teenagers preferred to use home computers for their work, and for their leisure, rather than the computers available at their school (Cuthell, 2002). For these teenagers, the distinction between work and play was difficult to recognize when they used their home computers (as they often engaged with leisurely activities while doing their work), which is in stark contrast to how schooling structures differentiate between work and play (Lynch, 2001, 2002). Their engagement with technology demonstrates that the use of one's home computer was both a site for leisure and learning, and for these teenagers there was sometimes little distinction between the two.

Within this field (of home computer use for leisure by teenage experts), there are sub-fields, and this field itself is a sub-field within other, larger fields. While leisure may be seen as the overall field, the sub-field of home computer use for leisure is home computer use by teenage experts. The learning that takes place within this sub-field positions the field as important within the broader field of leisure. Some of the teenagers realized that they were learning; some did not think they were learning all the time, but some did not believe that their everyday engagement with digital media constituted learning. For example, one of the participants did not think what they were doing had or could have any link to their schoolwork (Lisa), and some did not have much idea of how their interest and expertise could be linked to future careers (Tim, Lisa, Charli). So perhaps it was difficult for some of the participants to link their learning to school-like notions of learning. Jake was recognized for his expertise as he had allowances made in terms of enrolling in only three school subjects. This enabled him to contribute to the school through his administration of the computer network, and work within the sound and lighting venue at the school. Jake's alternative trajectory enabled his experiences at school to be more relevant for extra-curricular and future endeavours.

What the participants were learning at home was not only applicable to one field, that is, home computer use for leisure. As some of the participants did not see the relevance of schooling in their lives, we must explore whether traditional schooling is the best place for some technological experts to be. Their schooling was mainly positioned in the print culture of previous generations, in comparison to the digital world the teenagers were positioned in. If the world of information technology is all about keeping up with the latest and maintaining and increasing expertise at incredible rates, then the provision of the Internet and computers may be one way to connect technological expertise, relevance and the workforce. The scope for e-learning and blended learning within secondary schooling is something that can be explored as challenges can be made to those who privilege face-to-face learning, that is, classrooms of children being instructed by one teacher. This type of practice does not fit with collaborative social learning that focuses on interaction, personal interest, and active engagement - all within cyberspace.

This field can be considered to be a young field, and neither an established field of leisure nor a traditional field of expertise or learning, therefore it is in tension with other fields. For example, the field, the capital within the field, and those positioned within the field, tend not to be valued by those who are outside of the field. As esteem (or respect or admiration) is given to someone or something only if it is recognized or identified (Bourdieu, 1990, 2001), it is arguable that this field is neither valued nor esteemed and therefore those within the field have little power. 


\section{Conclusion}

Presentation of the data demonstrates the heterogeneity of this group. The participants navigated the field of home computer use for leisure in different ways, yet the actual practice of computer use for leisure was arguably similar. They each had different priorities for their leisure, and for their activities they did on the computer, but the similarity between maintaining friendships through instant chat and email and searching out topics of interest was notable. It is important to remember that for these students the act of performing and practising their expertise was vital for them to not only develop their expert skills but to believe in themselves as continuing experts. This confirms that expertise was a process for these participants: 'Belief is an inherent part of belonging to a field' (Bourdieu, 1990, p. 167). The practice evident in this field of home computer use for leisure of teenage experts constitutes an embodied way of life for these teenagers. This field of leisure provided them with the means to effectively learn about topics of interest to them which had developed their sense of being a technological expert, which suggests that this field of leisure should be valued by those who are not positioned in the field.

The structured structures in the lives of the participants led to further structuring structures (Bourdieu, 1990), which presents the inevitable, that is, that any child who is exposed to these forms of capital and has this type of Western youth habitus has the potential to develop a level of expertise, be it on the computer or in another field. Part of this habitus comprises 'keeping up' with their friends, that is, being familiar with a variety of media texts in order to communicate and socialize with their peers. Instant messaging and email have become the acceptable practice in this field and possibly in the larger field of leisure, and arguably can be constituted as a structure that perpetuates itself in the lives of these teenagers. These practices constitute the cyber-relations evident in this field of home computer use for leisure by some teenage technological experts.

\section{Note}

[1] http: / /www.piczo.com

\section{References}

Bourdieu, P. (1984) Distinction: a social critique of the judgement of taste. London: Routledge \& Kegan Paul.

Bourdieu, P. (1990) The Logic of Practice, trans. R. Nice. Cambridge: Polity Press.

Bourdieu, P. (1992) The Rules of Art. Cambridge: Polity Press.

Bourdieu, P. (1999) Understanding, in P. Bourdieu et al The Weight of the World: social suffering in contemporary society, 607-626. Cambridge: Polity Press.

Bourdieu, P. (2000) Pascalian Meditations, trans. R. Nice. Cambridge: Polity Press.

Bourdieu, P. (2001) Masculine Domination, trans. R. Nice. Cambridge: Polity Press.

Cuthell, J.P. (2002) Virtual Learning: the impact of ICT on the way young people work and learn. Aldershot: Ashgate.

Facer, K., Furlong, J., Furlong, R. \& Sutherland, R. (2003) ScreenPlay: children and computing in the home. London: RoutledgeFalmer.

Grenfell, M. (2004) Pierre Bourdieu: agent provocateur. London: Continuum.

Grenfell, M. \& James, D. (Eds) (1998) Bourdieu and Education: acts of practical theory. London: Falmer Press.

Grenfell, M. \& James, D. (2004) Change in the Field - changing the field: Bourdieu and the methodological practice of educational research, British Journal of Sociology of Education, 25(4), 508-523. http: / / dx.doi.org/10.1080/014256904200026989

Johnson, N.F. (2004) Technological Disadvantage of the Digital Age. Refereed paper presented at the annual conference of the Australian Association for Research in Education, University of Melbourne, November 28-December 2. http: / / www.aare.edu.au/04pap/joh04392.pdf

Johnson, N.F. (2009) The Multiplicities of Internet Addiction: the misrecognition of leisure and learning. Aldershot: Ashgate.

Kenway, J. \& Bullen, E. (2001) Consuming Children: education-entertainment-advertising. Buckingham: Open University Press. 
Lovell, T. (2000) Thinking Feminism with and against Bourdieu, in B. Fowler (Ed.) Reading Bourdieu on Society and Culture, 27-48. Oxford: Blackwell.

Lynch, J. (2001) Introducing Internet-Based Technologies: challenges for teachers and schools. Doctoral thesis, La Trobe University.

Lynch, J. (2002) What Can We Learn from McLuhan? Electronic Communication Technologies and the Future of Schooling. Refereed paper presented at the annual conference of the Australian Association for Research in Education. http:/ / www.aare.edu.au/02pap/lyn02031.htm (accessed 2 October 2007).

Merriam, S.B. (1998) Qualitative Research and Case Study Applications in Education, 2nd edn. San Francisco: Jossey-Bass.

Moi, T. (1991) Appropriating Bourdieu: feminist theory and Pierre Bourdieu's sociology of culture, New Literary History, 22(4), 1017-1049. http: / / dx.doi.org/10.2307/ 469077

Olson, H. (n.d.) Quantitative 'versus' Qualitative Research: the wrong question. University of Alberta. http: / / www.ualberta.ca/dept/slis/ cais/olson.htm (accessed 2 October 2007).

Patton, M.Q. (2002) Qualitative Research and Evaluation Methods, 3rd edn. Thousand Oaks: Sage.

Schwandt, T. (1990) Paths to Inquiry in the Social Disciplines: scientific, constructivist, and critical theory methodologies, in E.G. Guba (Ed.) The Paradigm Dialog, 258-276. Newbury Park: Sage.

Webb, J., Schirato, T. \& Danaher, G. (2002) Understanding Bourdieu. Crows Nest, NSW: Allen \& Unwin.

NICOLA F. JOHNSON is a lecturer in curriculum and teacher education at the Faculty of Education, University of Wollongong, Australia. Her current research focuses on the technological expertise of young people and the learning principles evidenced in the use of social network sites. Her first book, The Multiplicities of Internet Addiction: the misrecognition of leisure and learning, was published in February 2009 and she is currently working on her second book entitled, Publishing from your PhD: negotiating a crowded jungle. Correspondence: Nicola F. Johnson, Faculty of Education, University of Wollongong, Northfields Avenue, Wollongong, NSW 2522, Australia (nicolaj@uow.edu.au) 